\title{
Optimal Rail Transit System Planning Using a Geographic Information System and a Genetic Algorithm
}

\author{
Chro Ahmed ${ }^{1}$, Khalid Nur ${ }^{2}$, Washington Ochieng ${ }^{1}$
}

\begin{abstract}
- the planning of a rail transit system is a complex process involving the determination of station locations and rail line alignments connecting the stations. There are many requirements and constraints to be considered in the planning process, with complex correlations and interactions, necessitating the application of optimization models in order to realize reliable and cost-effective rail transit systems. Although various optimization models have been developed to solve the rail transit system planning problem, most neglect the complex interactions between station locations and associated rail lines linking them station by treating them in separate optimization processes. This is in addition to focusing mainly on a single objective system requirement and thus resulting in suboptimal solutions.

This paper addresses the limitations in the current approaches by developing an optimal planning methodology that treats the rail transit system and its influencing factors in a single integrated process using a geographic information system (GIS) and a genetic algorithm (GA). It accounts for local factors and multiple planning requirements that arise from passenger, operator and community objectives, while optimizing locations of stations and the associated rail line linking the stations simultaneously. The methodology is applied to the City of Leicester (United Kingdom) as a case study to demonstrate its capability for optimal rail transit system planning particularly in regions with complex topographies.
\end{abstract}

Keywords - Rail transit system, Rail transit station locations, Rail transit lines, Optimization, Genetic Algorithm, GIS.

\section{Introduction}

Rail transit systems have the potential to not only accommodate growth in traffic and congestion but also stimulate economic activities and provide a fast, reliable and convenient service for the population on major corridors and important activity areas. Their benefits are evident in the construction of new rail transit systems and expansion of existing ones in many cities despite their need for substantial investments. A basic rail transit system planning problem is to find economical locations of stations and configuration of rail lines linking the stations that can provide a high quality of service for passengers and wider benefits for operators and the community.

${ }^{1}$ Center for Transport Studies, Imperial College London. London SW7 2AZ United Kingdom.

c.ahmed11@imperial.ac.uk / w.ochieng@imperial.ac.uk

${ }^{2}$ Arup,

London, W1T4BQ, United Kingdom.

Khalid.Nur@arup.com
This requires the consideration of various local factors, including travel demand patterns, demography, topography, and existing transport networks while satisfying a set of constraints that arise from passenger, operator and community requirements. There are therefore many requirements, with complex correlations and interactions, to be considered, making rail transit system planning a very complex process. This necessitates the application of optimization models in order to realise reliable and costeffective rail transit systems.

In response, since the 1960s many researchers and planners have made many attempts to develop algorithms and application tools for rail transit system planning. Vuchic and Newell [1] developed an analytical approach to determine spacing between stations along a given rail line considering a linear transit line and a uniform passenger distribution along it. They solved a set of partial differential equations to minimize total passenger travel time. Subsequently, Vuchic [2], Wirasinghe [3], and Kikuchi \& Vuchic [4], considered various improvements to the Vuchic and Newell's approach for determining the optimal station spacing. A number of studies [5, 6] addressed the problem of optimizing the rail line length along with the consideration of various associated parameters, such as headway and train size that satisfy demand. However, these studies have only limited practical applications due to simplifying assumptions, such as uniform distribution of demand along rail transit lines and an underlying rectangular grid for both highways and railways. Recent studies, therefore, attempted to further improve these approaches through removing unrealistic assumptions and incorporating various planning and real world constraint requirements. Horner and Grubesic [7] exploited GIS tools to evaluate and locate terminals along urban rail lines. Laporte et al. [8] proposed a heuristic model to locate a specified number of stations on a predefined rail transit alignment with respect to the objective of maximum ridership, subject to interstation spacing constraint. The study estimated the ridership of each station by triangulation of census tracts, assuming that the percentage of captured travelers depends on their access distance from the station. Jha and Oluokun [9] addressed the determination of the optimal station locations along a given rail transit alignment using artificial intelligence based optimization techniques and GIS. Similarly, using GIS tools Samanta and Jha [10] used GA to seek the best set of station locations along a rail transit line to minimize total system cost while ensuring that interstation distances remain constraint. The model defined the total system cost as a function of passenger total travel time, system operation and construction costs. In an extended effort, Samanta and Jha [11] furthered their study to use different objective function of demand and cost. It is important to note that these studies addressed only the problem of station locations, assuming that the rail transit lines were predetermined. In contrast, a 
number of recent studies focused only on the determination of rail transit lines, assuming that station locations were given or predetermined. Jha and Schonfeld [12] adapted highway alignment optimization models [13, 14, 15] for optimizing a rail transit line alignment between a pair of predetermined stations. The objective functions and constraints were adjusted to reflect the rail transit design criteria. The objective functions of the developed model included minimizing passenger, operator and construction costs while satisfying the general geometric constraints of rail transit line alignment. In an extended effort, Lai and Schonfeld [16] proposed a model for optimizing a rail transit line alignment that can connect several predetermined stations. With the objective of minimizing the construction cost, a proposed heuristic model based on the GA and GIS generates the alignments through preset stations while satisfying geometry constraints of the rail line alignment. In a more recent study, Costa et al. [17] presented a heuristic model based on a simulated annealing algorithm to optimize high speed rail alignment configuration that minimizes an objective function considering construction costs while complying with demanding geometry, land use, and location constraints. The model considered that the high speed rail alignment configuration is defined by linear sections that connect a set of sequential of three dimensional (3D) points in space. Costa et al. [18] further improved the capability of this model in solving large problem size and complex interacting factors, typical of real-world decision making. The study presented the application of the model to a real world case study in Portugal based on real data. All the aforementioned models deal with either line alignment or station location optimization problems. Although widely used in rail transit system planning practice, these models cannot effectively capture the interactions between rail lines and station locations, resulting in sub-optimal solutions.

A number of researchers have tried to bridge this gap by integrating the determination of station locations and associated rail transit line linking the stations into a single optimization process. Dufourd et al. [19] addressed the problem of locating a rapid transit line with known terminus linking a fixed number of stations on a grid network. The model was formulated to maximize the total population covered by stations, subject to interstation spacing constraints. Similarly with respect to the objective of maximum population coverage, subject to interstation spacing constraints, Bruno et al. [20] presented a heuristic model for optimizing a rapid transit line and associated station locations. The proposed heuristic model was designed to construct the transit line alignment through gradual extension from a station to the consecutive station while satisfying interstation spacing and maximum population coverage. Laporte et al. [21] proposed a greedy algorithm for locating a rapid transit line alignment through a set of stations providing maximum traffic flow. The model was formulated as a longest-path problem to maximize captured traffic by the alignment, subject to a maximum length constraint. In an extended effort, Laporte et al. [22] incorporated the station location problem and multi transit lines with fixed origins and destinations. The model was formulated to maximize coverage of the traffic demand as an objective function and the construction cost as a constraint. This model was further extended by Marin [23] to incorporate the line location constraints with a bounded but variable number of lines, and lines with no fixed origins and destinations. Despite the capabilities of these models in considering the complex correlations and interactions between the two intertwined elements of rail transit system planning, most of these models mainly address partial aspects of the problem. This is by focusing mainly on the coverage of traffic demand or population with other critical passenger, operator and community related aspects, such as operation cost, coordination with land use pattern, integration with existing transport network and environmental requirements, being ignored. Thus these models also cover partial aspects of rail transit system planning.

This paper presents an integrated optimization methodology for determining rail transit station locations and associated line linking the stations while accounting for multiple requirements that arise from passenger, operator and community objectives. This methodology can (a) effectively determine station locations and a rail line linking the stations within the context of an integrated optimization process to obtain an optimal rail transit system, (b) incorporate the complex correlations and interactions between the rail transit line alignment and station locations by integrating these two intertwined elements into a single optimization process, (c) simultaneously consider multiple requirements and constraints of rail transit system planning in the evaluation process, (d) efficiently find a solution in large regions with complex topographies. The paper also proposes a genetic algorithm (GA)-based model to seek for solutions while interacting with the geographic information system (GIS) database.

The paper is organized as follows. Section 2 describes the framework of the methodology. Section 3 details how the designed method determines a large pool of potential station locations, followed by the description of the GAbased algorithm to determine the optimal configuration of the system in section 4 . The application of the model in a real world case study is demonstrated in section 5 with concluding remarks in section 6 .

\section{The Methodology Framework}

The proposed methodology brings together the various rail transit station planning requirements of the different stakeholders; passengers, operator and community, and incorporates them into a single integrated planning platform. It simultaneously determines an optimal set of station locations and rail line alignment to link the stations within the context of an integrated optimization process to obtain the final system configuration. In addition, prior to the optimization process it performs a feasibility analysis of the potential study area to identify a set of feasible station locations based on a comprehensive consideration of various requirements on topological features, population coverage, integration with the existing transport modes and land values. This helps rail transit planners to initially evaluate different station locations, which can effectively speed up the planning process and improve decision making capabilities in selecting reliable and cost effective solution alternatives. Section 3 and 4 presents further details of 
measuring the feasibility of station sites and the integrated optimization process.

\section{Feasibility Analysis of Potential Station Locations}

Using GIS tools, the proposed methodology evaluates the feasibility of station sites with respect to various rail transit planning requirements, such as coordination with land use patterns, population coverage, integration with existing transport modes, stimulation of various economic activities and construction costs. GIS tools have been widely deployed in solving transport design problems due to their ability to manage and process large amounts of real data such as land value, land use patterns, topographic information, and existing street networks in addition to performing some basic spatial analysis. The following five steps are applied to screen the potential served area and perform evaluation and comparative analysis for generating feasible locations of rail transit stations.

Step 1: divides the study area into grids (Gi) and creates a GIS layer $\left(\Omega_{g}\right)$ for stations. It is assumed that each of the generated grids represents a potential location of a rail station. Therefore, the size of the grid should represent the typical size of a rail station.

Step 2: evaluates the locations of the station grids (Gi) with respect to various rail transit planning requirement criteria, which includes computing average population density, commercial land use density, land values, intensity of airport terminals, bus stops and car parking facilities clustered within a defined walking distance to stations.

Step 3: finds all station grids that intersect with the environmental sensitive areas and exclude them from the search space of potential station locations. This is done by overlaying the generated station grid layer $\left(\Omega_{g}\right)$ over the environmental sensitive areas layers $\left(\Omega_{\mathrm{e}}\right)$ to generate the feasible grid layer for stations $\left(\Omega_{\mathrm{f}}\right)$. The environmental sensitive areas include historic buildings, national parks, woodlands, forests, rivers and sites of scientific interest.

$$
\Omega_{f}=\Omega_{g} \cap \overline{\Omega_{e}}
$$

Step 4: identifies all the grids within the feasible station layer $\left(\Omega_{\mathrm{f}}\right)$ that satisfy the predefined conditions set by the threshold values of the rail transit requirement criteria and assigns them with integer values, which represent the weight of the satisfied criteria, as follow:

$$
\forall G_{\mathrm{i}} \in \Omega_{f} \rightarrow S^{\mathrm{i}}=\left\{1 \text {, if }\left(\overline{P D} \mid D_{w}\right) \geq V_{P D}\right.
$$

Where:

PD is the average Population Density within the defined walking distance;

$\mathrm{D}_{\mathrm{w}}$ is the defined walking distance; and

$V_{\mathrm{PD}}$ is pre-specified threshold value of average population density within $\mathrm{D}_{\mathrm{w}}$.

Where:

$$
\forall G_{\mathrm{i}} \in \Omega_{\mathrm{f}} \rightarrow \mathrm{S}^{\mathrm{i}}=\left\{\mathbb{1}_{,} \text {if }\left(\Sigma \overline{C A} \mid \mathrm{D}_{\mathrm{w}}\right) \geq \mathrm{V}_{\mathrm{CA}}\right.
$$

CA is commercial land use areas within $\mathrm{D}_{\mathrm{w}}$,

$V_{C A}$ is the pre-specified threshold value of commercial land use area within $\mathrm{D}_{\mathrm{w}}$. commercial land uses include including office complexes, retail areas, recreational centers and central business districts.

$\forall G_{\mathrm{i}} \in \Omega_{\mathrm{f}} \rightarrow \mathrm{S}^{\mathrm{i}}=$

$\left\{1_{s}\right.$ if $\left(\sum \mathrm{DA} \mid \mathrm{D}_{\mathrm{w}}\right) \geq \mathrm{N}_{\mathrm{DA}}$ OR if $\left(\sum \mathrm{DP} \mid \mathrm{D}_{\mathrm{w}}\right) \geq \mathrm{N}_{\mathrm{DP}}$

Where:

DA is the Declined Areas that need regeneration or area of undeveloped land parcels that have strong potential for future economic developments within $\mathrm{D}_{w}$;

$\mathrm{N}_{\mathrm{DA}}$ is the pre-specified threshold value of declined areas/undeveloped land parcels within $\mathrm{D}_{w}$;

DP is the area of existing development projects within $\mathrm{D}_{\mathrm{w}}$; $\mathrm{N}_{D p}$ is the pre-specified threshold area of development projects within $\mathrm{D}_{\mathrm{w}}$.

$$
\forall \mathrm{G}_{\mathrm{i}} \in \Omega_{\mathrm{f}} \rightarrow \mathrm{S}^{\mathrm{i}}=\left\{1_{\text {, if }}\left(\overline{\mathrm{LV}} \mid \mathrm{D}_{\mathrm{w}}\right) \leq \mathrm{V}_{\mathrm{LV}}\right.
$$

Where:

$\overline{\mathrm{LV}}_{\text {is }}$ the average Land Value within $\mathrm{D}_{\mathrm{w}}$; and

$V_{L V}$ is the pre-specified threshold value of maximum allowed land acquisition value (unit cost per unit area) for stations.

$$
\forall G_{\mathrm{i}} \in \Omega_{\mathrm{f}} \rightarrow \mathrm{S}^{\mathrm{i}}=\left\{1, \text { if }\left(\sum A T \mid \mathrm{D}_{\mathrm{w}}\right) \geq \mathrm{N}_{\mathrm{AT}}\right.
$$

Where:

AR is the number of airport terminals (if any) within $D_{w}$; $\mathrm{N}_{\text {AT }}$ is the pre-specified threshold number of airport terminals within $\mathrm{D}_{\mathrm{w}}$.

$\forall \mathrm{G}_{\mathrm{i}} \in \Omega_{\mathrm{f}} \rightarrow \mathrm{S}^{\mathrm{i}}=$

$\left\{1\right.$, if $\left(\sum \mathrm{CP} \mid \mathrm{D}_{\mathrm{w}}\right) \geq \mathrm{N}_{\mathrm{CP}}$ OR if $\left(\sum B P \mid \mathrm{D}_{\mathrm{W}}\right) \geq \mathrm{N}_{\mathrm{BP}}$

Where:

$\mathrm{CP}$ is the number of car parks within $\mathrm{D}_{\mathrm{w}}$;

$\mathrm{N}_{\mathrm{CP}}$ is pre-specified threshold number of car parks within $\mathrm{D}_{\mathrm{w}}$;

$\mathrm{BP}$ is the number of bicycle parking facilities within $\mathrm{D}_{\mathrm{w}}$; $\mathrm{N}_{\mathrm{BP}}$ is pre-specified threshold number of bicycle parking facilities within $\mathrm{D}_{\mathrm{w}}$.

$$
\forall G_{\mathrm{i}} \in \Omega_{\mathrm{f}} \rightarrow \mathrm{S}^{\mathrm{i}}=\left\{1_{v} \text { if }\left(\sum B S \mid \mathrm{D}_{\mathrm{w}}\right) \geq \mathrm{N}_{\mathrm{BS}}\right.
$$

Where:

BS is the number of Bus Stops within $\mathrm{D}_{\mathrm{w}}$; and

$\mathrm{N}_{\mathrm{BS}}$ is pre-specified threshold number of bus stops within $\mathrm{D}_{\mathrm{w}}$.

The weight (integer values) attributed to each condition represents the degree of importance of the corresponding requirement criteria; the higher the weight, the more the degree of importance. In equations (2)-(8), however, equal weights of 1 are assigned to all the requirement criteria. A rail transit system is a major, high investment, and permanent structure. Therefore, it should not be solely linked to a single objective but also equally viewed in the broad context of the mobility, socio-economic and 
environment improvements. Nonetheless, the model is designed in a way that it can be adopted easily to accommodate different weights for different requirement criteria, for cases where the prioritization of a particular requirement is necessary.

Step 5: aggregates the weights of the requirement criteria satisfied by station grids and designate all grids that meet the pre-defined satisfaction level.

In this paper, the satisfaction level is defined as minimum aggregate weight of the requirement criteria to be met by the potential station locations. Therefore, the higher the satisfaction level, the larger the number of requirement criteria needed to be satisfied by station grids. Due to the conflicting nature of some of the requirements, such as land value and commercial land uses areas, it is very difficult to find a sufficient number of locations that can satisfy all the requirement criteria. The satisfaction level is therefore, implemented in the proposed model to enable rail transit planners to make trade-off among the contradictory requirements and obtain a practical number of feasible station locations for the optimization process to choose from.

\section{Simultaneous Optimization of Rail Transit Line and associated Station Locations}

The proposed model starts with seeking the final configuration of the proposed system within the context of an integrated optimization process once it measures the feasibility of station sites. It simultaneously selects the best set from the identified potential station pool along with generating the best line to link the selected stations. In addition to the comprehensive consideration of various local factors, including travel demand pattern, land use pattern, and topography, the proposed optimization model accounts for the multiple requirements of the rail transit stakeholders; passenger, operator and community. Due to the complexity of the rail transit system planning requirements which involve non differentiable, nonlinear, discontinuous structure, it is difficult to model them with simple mathematical functions. Therefore, a heuristic search method based on GA is designed to efficiently solve the problem. Besides, GIS is embedded within the search method, which can efficiently retrieve and analyze large amounts of real data such as land value, land use patterns, topographic information and existing street network and thus makes the GA search algorithm more efficient to find robust solutions.

The optimization model aims to realize a rail transit system that can efficiently provide a high service quality and benefits for both passenger and community with acceptable capital and operation costs. Therefore, the objective of the optimization process is to minimize passenger, operator and community costs. The formulations of the objective functions are further elaborated below:

1- Passenger cost: is formulated to calculate time cost difference between utilizing rail and other transport modes, specifically bus and car. Assuming the proposed system offer service on a daily basis, the annual passenger cost $\left(\mathrm{P}_{\mathrm{c}}\right)$ is:

$$
\begin{aligned}
& \mathrm{P}_{\mathrm{c}}=365 \times \Sigma_{\mathrm{t}} \Sigma_{\mathrm{i}} \Sigma_{\mathrm{j}}\left(\left(\mathrm{P}_{\mathrm{ij}} \times \mathrm{T}_{\text {Cttij }}-\mathrm{P}_{\text {cij }} \times \mathrm{T}_{\text {Ctcij }}\right)+\right. \\
& \left.\left(\mathrm{P}_{\mathrm{ij}} \times \mathrm{T}_{\text {Cttij }}-\mathrm{R}_{\text {bij }} \times \mathrm{T}_{\text {Ctbij }}\right)\right)
\end{aligned}
$$

Where:

$P_{i j}$ is the number of railway passengers;

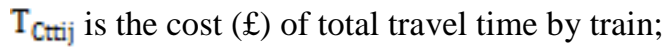

$P_{\text {cij }}$ is the number of railway passengers that may switch to the car if the rail system is not available;

$\mathrm{T}_{\text {Ctcij }}$ is the cost $(£)$ of total travel time by car;

$P_{\text {bij }}$ is the number of railway passengers that may switch to the bus if the rail system is not available;

$\mathrm{T}_{\text {Ctbij }}$ is the cost ( $£$ ) of total travel time by bus;

All these parameters are evaluated for travelling from zone i to zone $\mathrm{j}$ in time period $\mathrm{t}$.

The cost of total travel time by train, car and bus is:

$$
\begin{aligned}
\mathrm{T}_{\mathrm{Ctt}}=\mathrm{T}_{\mathrm{ta}} \times \mathrm{A}_{0}+\mathrm{T}_{\mathrm{tw}} \times \mathrm{W}_{0}+\mathrm{T}_{\mathrm{tt}} \times \mathrm{T}_{0} \\
\mathrm{~T}_{\mathrm{Ctc}}=\mathrm{T}_{\mathrm{ct}} \times \mathrm{T}_{0}+\mathrm{T}_{\mathrm{cs}} \times \mathrm{S}_{0} \\
\mathrm{~T}_{\mathrm{Ctb}}=\mathrm{T}_{\mathrm{ba}} \times \mathrm{A}_{0}+\mathrm{T}_{\mathrm{bw}} \times \mathrm{W}_{0}+\mathrm{T}_{\mathrm{bt}} \times \mathrm{T}_{0}
\end{aligned}
$$

Where:

$\mathrm{T}_{\mathrm{tg}}$ is access time to/from rail stations (min);

$\mathrm{A}_{0}$ is the unit costs of access time (£/min);

$\mathrm{T}_{\mathrm{tw}}$ is waiting time at rail stations; $W_{0}$ is the unit costs of waiting time ( $£ / \mathrm{min})$;

$\mathrm{T}_{\mathrm{tt}}$ is on train travel time (min);

$T_{0}$ is the unit cost of on train/ in-car travel / on- bus time (£/min) ;

$\mathrm{T}_{\text {ctt }}$ is in-car travel time ( $\left.\mathrm{min}\right)$;

$\mathrm{T}_{\mathrm{Cs}}$ is search time for a park (min);

$S_{0}$ is the unit cost of search time for a parking space (£/min);

$\mathrm{T}_{\text {tb }}$ is access time to/from bus stations (min);

$\mathrm{T}_{\mathrm{tw}}$ is waiting time at bus stops; and

$\mathrm{T}_{\mathrm{bt}}$ is on-bus travel time ( $\mathrm{min}$ ).

In this paper, it is assumed that the passenger demand for different time periods (AM and PM peak, intermediate peak and off peak periods), is provided exogenously. It is also assumed that the car and bus travel time elements between each traffic analyses zone pair of the potential study area at each time periods (AM, IP, OP and PM) are assumed to be obtainable from relevant transport agencies, while travel time elements of the train are calculated through equations (13) to (15).

The passenger access time to/from rail stations is a function of the passenger walking distance and speed to/from stations. It is computed through artificial links created between traffic analysis zones (TAZs) and potential station locations. These links measure the distance between the centroids of the each TAZ and potential station location $\left(D_{a}\right)$, thus the access time is calculated by dividing this distance $\left(D_{a}\right)$ to passenger walking distance $\left(V_{\alpha}\right)$. 


$$
T_{a}=\frac{D_{a}}{V_{a}}
$$

The waiting time is assumed to be equal to half of the train headway ( $H_{\mathrm{W}}$ ) which is function of train frequency.

$$
T_{w}=\frac{1}{2} H_{w}
$$

The on-train travel time is calculated by dividing the distance between boarding and alighting station $\left(D_{s}\right)$ by the train speed $\left(V_{t}\right)$.

$$
T_{\mathrm{t}}=\frac{D_{x}}{V_{\mathrm{t}}}
$$

2- Operation cost: is formulated to calculate the operation and maintenance cost differences between utilizing rail and other transport modes (specifically the car and bus) which is derived as a function of each mode corresponding travelled distance and potential passengers. Thus the annual operation cost $\left(\mathrm{O}_{c}\right)$ is calculated as follows assuming the train offers services on a daily basis:

$$
\begin{aligned}
& \mathrm{O}_{\mathrm{c}}=365 \times \Sigma_{\mathrm{t}} \Sigma_{\mathrm{i}} \Sigma_{\mathrm{j}}\left(\left(\mathrm{P}_{\mathrm{ij}} \times \mathrm{L}_{\mathrm{tij}} \times \mathrm{M}_{\mathrm{to}}-\mathrm{P}_{\mathrm{cij}} \times \mathrm{L}_{\mathrm{cij}} \times\right.\right. \\
& \left.\left.\mathrm{M}_{\mathrm{c} 0}\right)+\left(\mathrm{P}_{\mathrm{ij}} \times \mathrm{L}_{\mathrm{tij}} \times \mathrm{M}_{\mathrm{to}}-\mathrm{P}_{\mathrm{bij}} \times \mathrm{L}_{\mathrm{bij}} \times \mathrm{M}_{\mathrm{b} 0}\right)\right)
\end{aligned}
$$

Where:

$\mathrm{L}_{\mathrm{tij}}$ is the train $\mathrm{km}$ travelled distance;

$M_{t 0}$ is unit operation and maintenance cost for train ( $E /$ passenger-km);

$\mathrm{L}_{\mathrm{cij}}$ is the car $\mathrm{km}$ travelled distance;

$\mathrm{M}_{\mathrm{L} 0}$ is unit operation cost for car ( $\mathbb{E} /$ passenger- $\mathrm{km}$ );

$\mathrm{L}_{\mathrm{bij}}$ is the bus km travelled distance; and

$\mathrm{M}_{\mathrm{bo}}$ is unit operation cost for bus ( $E /$ passenger-km).

All travelled distances are evaluated from zone $\mathrm{i}$ to zone $\mathrm{j}$ in time period $\mathrm{t}$.

3- Community costs are modeled to comprise the construction costs of the system. These include the capital cost incurred in constructing the stations and associated line connecting the stations. The capital cost of stations covers the land acquisition costs, building cost and equipping the stations with necessary facilities. The capital cost of the rail line connecting the stations comprises of track and tunnel related costs.

$$
\mathrm{C}_{0}=S_{1}+S_{\tilde{b}}+T u+T r
$$

Where:

$\mathrm{S}_{\mathrm{i}}$ is cost of stations' right of way acquisition ;

$S_{\vec{b}}$ is cost of building and equipping the stations with necessary ;

$T u$ is tunnel cost of the rail line connecting the stations; and $T r$ is track cost of rail line connecting the stations.

The land acquisition costs are fed into the evaluation process via interaction with GIS. The cost of building and equipping stations are assumed to be fixed. The cost of tunnel construction is calculated by multiplying predefined unit cost of tunnel construction $\left(C_{T_{e}}\right)$ by tunnel length and tunnel cross section area. The track cost is a linear function of the rail line length, and is calculated by multiplying the line track length by unit track $\operatorname{cost}\left(C_{T r}\right)$.

With the objective of minimizing the total system cost which is a function of the above three formulated objective functions, the optimization algorithm addresses the essential trade-offs between contradictory requirements of rail transit system planning, particularly between rail system patronage and investment costs. To deliver adequate service quality for railway passengers, the algorithm tries to either decrease passengers' rail travel time compared to bus and car travel time or increase railway riders or a combination of the two through the passenger cost function. It also tries to increase the system revenue gains and achieve an economically efficient system operation through the operation cost function. This function calculates the total operation and maintenance cost reductions that can be achieved by using rail instead of the other motorized transport modes, thus the algorithm tries to increase the railway ridership in order to increase this reduction to a maximum possible limit. Furthermore, through the community cost function the algorithm tries to minimize the investment costs. The optimization algorithm therefore resolves the trade-offs by trying to increase the railway riders to reduce both the passenger and operation costs, while not increasing the investment costs too much. This implies the algorithm may increase the investment costs to a certain extent to accommodate more railway patronage, and on the other hand it reduces passenger and operator costs by attracting more car and bus users to switch to rail.

In addition, a number of constraints are embedded in generating network configuration solution alternatives in order to achieve high efficiency of the proposed system in terms of both operation and functionality. These constraints are: , $\mathrm{Ns}_{\min } \leq \mathrm{Ns} \leq \mathrm{Ns}_{\max }$

ii. distance between stations, $\Delta \mathrm{s}_{\min } \leq \Delta \mathrm{s} \leq \Delta \mathrm{s}_{\max }$;

iii. population coverage by the rail line connecting the stations, $\mathrm{Pn} \geq \mathrm{Pn}_{\min }$

The first two constraints significantly influence the passenger total travel time, operator productivity and construction cost of the system. Therefore, incorporating them into the optimization process is essential for controlling operational requirements and achieving an economical rail transit system. The last constraint reflects the level of both population service and operation productivity offered by the system. The consideration of this aspect in generating alternative solutions is also crucial to guarantee an effective interconnection between the proposed rail system and the area it serves.

With respect to the objective of minimum total system cost, which is a function of the formulated passenger, operator and community objectives, and while satisfying the station and rail line configuration related constraint sets, the 
Proc. of the Fourth Intl. Conf. Advances in Civil, Structural and Mechanical Engineering- CSM 2016

Copyright (C) Institute of Research Engineers and Doctors, USA .All rights reserved.

ISBN: 978-1-63248-093-4 doi: 10.15224/ 978-1-63248-093-4-48

designed GA-based algorithm seeks the search space for the optimal solution of the following problem:

$$
\operatorname{Minimize}\left(\mathrm{T}_{\mathrm{c}}=\varphi p \mathrm{P}_{\mathrm{c}}+\varphi_{\mathrm{o}} \mathrm{O}_{\mathrm{c}}+\varphi \mathrm{c} \mathrm{C}_{\mathrm{c}}\right)
$$

Subject to $N s_{\min } \leq N s \leq N s_{\max }, \Delta s_{\min } \leq \Delta \mathrm{s} \leq \Delta s_{\max }$ and

$$
\mathrm{Pn} \geq \mathrm{Pn}_{\min }
$$

Where: $\mathrm{T}_{\mathbb{c}}$ is total system cost, and $\varphi p, \varphi o$ and $\varphi c$ are the coefficient of passenger, operator and community cost respectively. The main reason of integrating these coefficients into the evaluation process is to incorporate flexibility into the model to allow rail transit planners to prioritize a particular stakeholder requirement over the others when required.

\section{Case Study}

The effectiveness of the proposed methodology has been evaluated using a real world case study of the City of Leicester (United Kingdom). Considering an underground rail transit system and adopting the input parameters presented in table 1, the proposed model has been applied to design a rail transit system for the city based on a set of prelocated terminal stations. The locations of the terminal stations are determined based on the travel demand pattern of the city.
Figure 1 presents the optimal locations of stations and rail transit line connecting the stations, which represents the trade-off between the passenger and operator and community objectives. The optimal solution consists of 7 stations and an $8.04 \mathrm{~km}$ length of line connecting the stations. It is also interesting to note that the obtained solution services more than 75000 people within 800 meters walking distance of the stations, which comprise almost $23 \%$ of the entire city population. This is in addition to covering more than $19 \%$ of the city's important activity centers, which include shopping malls, recreational areas and office complexes, within 800 meters walking distance of the stations. These results, therefore, indicate that the output solution is promising and the developed model can effectively find robust and reliable solutions.

\begin{tabular}{|c|c|c|}
\hline Parameters & Description & Values \\
\hline$\overline{V_{t}}$ & train travel speed & $50 \mathrm{~km} / \mathrm{hr}$ \\
\hline$\overline{V_{a}}$ & passenger walking speed & $4 \mathrm{~km} / \mathrm{hr}$ \\
\hline$H_{W}$ & train headway & $10 \mathrm{~min}$ \\
\hline $\mathrm{A}_{0}$ & unit cost of access time & $£ 14 / \mathrm{hr}$ \\
\hline$W_{0}$ & unit cost of waiting time & $£ 14 / \mathrm{hr}$ \\
\hline$T_{0}$ & unit cost of in train travel time & $£ 7 / \mathrm{hr}$ \\
\hline$S_{0}$ & unit cost of search time for parking space & $£ 14 / \mathrm{hr}$ \\
\hline $\mathrm{M}_{\text {to }}$ & unit operation and maintenance cost for train & $£ 0.21 /$ passenger-Km \\
\hline $\mathrm{M}_{\mathrm{CO}}$ & unit operation and maintenance cost for car & $£ 0.30 /$ passenger-Km \\
\hline $\mathrm{M}_{\mathrm{bo}}$ & unit operation and maintenance cost for bus & $£ 0.15 /$ passenger-Km \\
\hline$S_{\text {b }}$ & costs of building and equipping the stations with necessary facilities & $£ 10^{6} /$ station \\
\hline$C_{T s}$ & unit cost of tunnel excavation & $£ 630 / \mathrm{m}^{3}$ \\
\hline$C_{\mathrm{Tr}}$ & unit cost of track & $£ 650 / \mathrm{m}$ \\
\hline $\mathrm{Ns} s_{\min }$ & Minimum number of stations & 5 stations \\
\hline $\mathrm{Ns} s_{\max }$ & maximum number of stations & 10 stations \\
\hline$\Delta \mathrm{s}_{\min }$ & minimum spacing between stations & $800 \mathrm{~m}$ \\
\hline$\Delta \mathrm{s}_{\max }$ & maximum spacing between stations & $1500 \mathrm{~m}$ \\
\hline $\mathrm{Pn}_{\min }$ & Minimum population coverage rate by the rail line & $60 \%$ \\
\hline$\varphi \mathrm{p}$ & coefficient of passenger cost & 1 \\
\hline$\varphi \circ$ & coefficient of operator cost & 1 \\
\hline$\varphi \mathrm{c}$ & coefficient community cost & 1 \\
\hline
\end{tabular}

Table 1: Values of the Optimization Model Input Parameters 
Proc. of the Fourth Intl. Conf. Advances in Civil, Structural and Mechanical Engineering- CSM 2016

Copyright (C) Institute of Research Engineers and Doctors, USA .All rights reserved.

ISBN: 978-1-63248-093-4 doi: 10.15224/ 978-1-63248-093-4-48

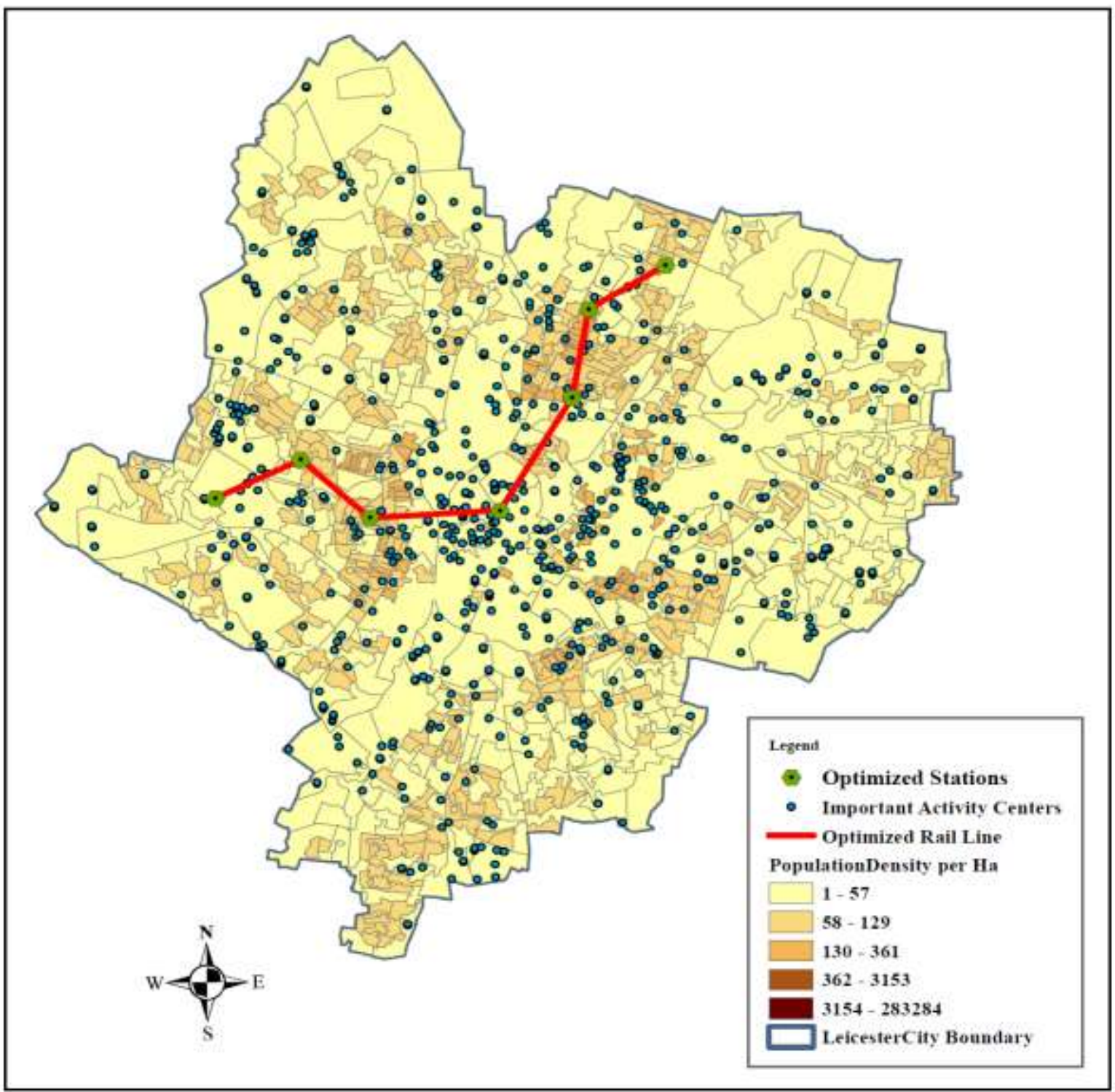

Figure 1: The generated optimal solution

\section{Conclusion}

The paper presents a practical planning methodology for a rail transit system that can effectively determine station locations and a rail transit line connecting the stations in an integrated optimization process. The proposed methodology screens the potential study area, prior to the optimization process, to identify a pool of feasible station locations based on the various rail transit planning requirements. This helps transit rail planners to initially evaluate different station locations, which can effectively speed up the planning process and improve decision making capabilities in selecting reliable and cost effective solution alternatives.

Consequently, the proposed methodology uses a developed a Genetic Algorithm- based solution algorithm to concurrently identify an optimum set of station locations from the pool of feasible stations and define the rail transit line connecting them while interacting with a supporting Geographic Information System (GIS).
The generated system satisfies constraints both for stations and line alignment configuration, and achieves the desirable trade-off between the passengers, operator and community related requirements.

The methodology was applied to a real world case study, City of Leicester (UK), to demonstrate its effectiveness in finding good solutions in large scale regions with complex topographical features. A rail transit system is designed for the city based on pre-located terminal stations. The results showed that the model is able to determine "good" solutions effectively in regions with complex topographical features. 


\section{Acknowledgment}

The authors would like to acknowledge the Higher Committee of Education in Iraq for supporting this research.

\section{References}

[1] G. Eason, B. Noble, and I. N. Sneddon, "On certain integrals of Vuchic, V. R., and G. F. Newell, "Rapid Transit Interstation Spacing for Minimum Travel-time," Transportation Science, vol. 2, no. 4, 1968, pp. 359-374.

[2] Vuchic, V.R., "Rapid Transit Interstation Spacings for Maximum Number of Passengers," Transportation Science, vol.3, no.3, 1969, pp.214-232

[3] Wirasinghe, S. C., "Nearly Optimal Parameters for a Rail/Feeder-Bus System on a Rectangular Grid," Transportation Research A, vol. 14, 1980, pp. 33-40.

[4] Kikuchi, S. and Vuchic, V.R., "Transit Vehicle Stopping Regimes and Spacings," Transportation Science, vol.16, no.3, 1982, pp.311-331.

[5] Wirasinghe, S.C., and Seneviratne, P., "Rail Line Length in an Urban Transportation Corridor," Transportation Science, vol.20, 1986, pp.237-245

[6] Chien, S., and Schonfeld, P., "Optimization of Grid Transit System in Heterogeneous Urban Environments," Journal of Transportation Engineering, vol.123, no.1, 1997, pp.28-35.

[7] Horner, M. W. and Grubesic, T. W., "A GIS-based Planning Approach to Locating Urban Rail Terminals," Transportation, vol.28, 2001, pp. 55-77.

[8] Laporte, G., Mesa, J. A. and Ortega, F. A., "Locating Stations on Rapid Transit Lines," Computers \& Operations Research, vol.29, 2002, pp. 741-759.

[9] Jha, M. K. and Oluokun, C., "Optimizing Station Locations along Transit Rail Lines with Geographic Information Systems and Artificial Intelligence," In Computers in Railways IX (COMPRAIL 2004), J. Allan, C. A. Brebbia, G. Sciutto, and S. Sone, Eds., WIT Press, Southampton, United Kingdom, 2004.

[10] Samanta, S. and Jha, M., "Identifying Feasible Locations for Rail Transit Stations: Two-Stage Analytical Model," Journal of the Transportation Research Board, vol.2063, 2008, pp. 81-88

[11] Samanta, S. and Jha, M.K, "Modeling a Rail Transit Alignment Considering Different Objectives," Transportation Research, Part A, vol.45, no.1, 2011, pp.31-45.

[12] Jha, M. K. and Schonfeld, P., "Optimizing Rail Transit Routes with Genetic Algorithms and Geographic Information System," Journal of Urban Planning and Development, vol.133, 2007, pp.161-171.

[13] Jong, J. C., "Optimizing Highway Alignments with Genetic Algorithms," Ph.D. Dissertation, University of Maryland, 1998.

[14] Jha, M.K., "A Geographic Information Systems-Based Model for Highway Design Optimization," Ph.D. Dissertation, University of Maryland, 2000.

[15] Kim, E., "Modeling Intersections \& Other Structures in Highway Alignment Optimization," Ph.D. Dissertation, University of Maryland, 2001.

[16] Lai, X. and Schonfeld, P., "Optimizing Rail Transit Alignments Connecting Several Major Stations," Compendium of Papers of the 89th TRB Annual Meeting, Washington, D.C., 2010.

[17] Costa, A. L., Cunha, C., Coelho, P. a. L. F., and Einstein, H. H. "Solving high-speed rail planning with the simulated annealing algorithm," Journal of Transportation Engineering, vol.140, 2014, pp.1-11.

[18] Costa, A., Cunha, M., Coelho, P., and Einstein, H., "Decision Support Systems for Real-World High-Speed Rail Planning," Journal of Transportation Engineering, vol. 142, 2016, pp. 1-10.

[19] Dufourd, H., Gendreau, M. and Laporte, G., "Locating a Transit Line Using Tabu Search," Transportation Science, vol.4, 1996, pp. 1-19.

[20] Bruno, G., Gendreau, M. and Laporte, G., "A Heuristic for the Location of a Rapid Transit Line," Computers \& Operations Research, vol.29, 2002, pp. 1-12.
[21] Laporte, G., Mesa, J., Ortega, F. and Sevillano, I., "Maximizing Trip Coverage in the Location of a Single Rapid Transit Alignment," Annals of Operations Research, vol.136, 2005, pp. 49-63.

[22] Laporte, G., Marín, Á., Mesa, J., and Ortega, F. , “An Integrated Methodology for the Rapid Transit Network Design Problem," In Algorithmic Methods for Railway Optimization, Lectures Notes in Computer Science, Geraets, F., Kroon, L., Schoebel, A., Wagner, D. \& Zarioliagis, C., Eds., Springer, Berlin, vol.4359, 2007, pp.187-199.

[23] Marín, Á., “An Extension to Rapid Transit Network Design Problem," Top, vol.15, 2007, pp. 231-241.

About Authors:

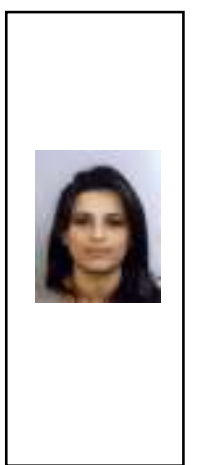

Miss Chro Ahmed is a Ph.D. candidate at the Centre for Transport Studies at Imperial College London. Her research is primarily focused on rail transit system planning which includes optimal location of station locations and associated line network linking the stations. She holds an MSc in Transport Engineering and a BSc in Civil Engineering.

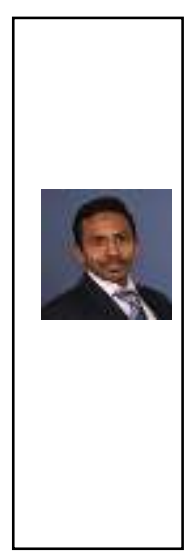

Dr.Khalid Nur is a senior Smart Mobility and ITS engineer with over 8 years of research and consultancy experience in transport and technology systems with special expertise in ITS enabling technologies. He holds a $\mathrm{PhD}$ in Wireless Positioning Systems from Imperial College London (UK), an MSc in Communications and Signal Processing from Newcastle University (UK) and a BSc in Electrical Eng. From Khartoum University (Sudan).

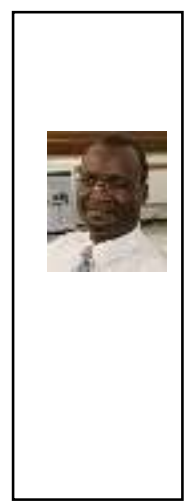

Professor Washington Yotto Ochieng is the Head of the Centre for Transport Studies and Chair of Positioning and Navigation Systems in the Department of Civil and Environmental Engineering at Imperial College London. He is also the Director of the Imperial College Engineering Geomatics Group (ICEGG). 